\title{
Hypertension, pregnancy and weather: is seasonality involved?
}

\author{
Brena Melo ${ }^{1}$, Melania Amorim² ${ }^{2}$ Leila Katz ${ }^{3}$, Isabela Coutinho ${ }^{4}$, José Natal Figueiroa ${ }^{5}$ \\ ${ }^{1} \mathrm{MSc}$ in Maternal and Child Health by the Institute of Integrative Medicine Professor Fernando Figueira - IMIP, Recife, PE, Brazil \\ ${ }^{2} \mathrm{PhD}$ in Obstetrics and Gynecology by the Campinas State University - UNICAMP, Campinas, SP, Brazil \\ ${ }^{3}$ PhD in Obstetrics and Gynecology by the Campinas State University - UNICAMP, Campinas, SP, Brazil \\ ${ }^{4} \mathrm{PhD}$ in surgery by the Federal University of Pernambuco - UFPE, Recife, PE, Brazil \\ ${ }^{5} \mathrm{PhD}$ in Maternal and Child Health by the Institute of Integrative Medicine Professor Fernando Figueira - IMIP, Recife, PE, Brazil
}

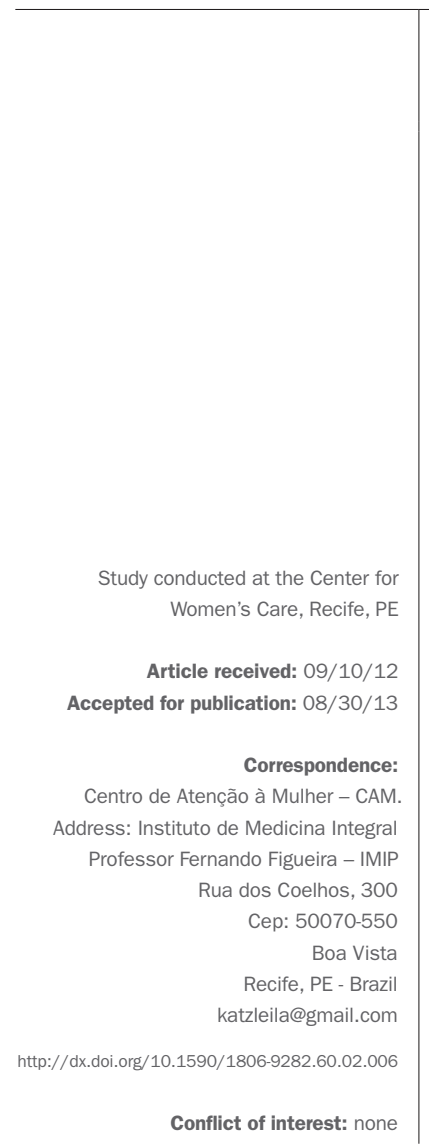

\section{SUMmARY}

Objective: The present study aimed at assessing the association between environmental temperature and the relative humidity of the air with frequency of hypertensive disorders of pregnancy.

Methods: A prospective and retrospective, descriptive, ecological study was held at a teaching maternity in Recife, Brazil. Data from all 26.125 pregnant women admitted between 2000 and 2006 were analysed and 5.051 had the diagnosis of hypertensive disorder of pregnancy. The incidence percentages were calculated monthly per deliveries. Data on mean monthly temperature and relative humidity of the air were collected and monthly comparisons were conducted. February was chosen as the reference month due to its lowest incidence of the disease. The relative chance of hypertensive disorders of pregnancy for each other month was estimated by odds ratio and Pearson's correlation coefficient was used to calculate the relation between the incidence of hypertensive disorders of pregnancy and the mean monthly temperature and relative air humidity.

Results: February presented the lowest mean monthly incidence $(9.95 \%)$ and August the highest (21.54\%). Pearson correlation coefficient revealed a higher incidence of hypertensive disorders of pregnancy in the cooler months $(\mathrm{r}=-0.26$; $\mathrm{p}=0.046)$ and no significant effect of relative air humidity $(\mathrm{r}=0.20 ; \mathrm{p}=0.128)$.

Conclusion: The incidence of hypertensive disorders of pregnancy may be affected by variations in temperature, increasing during cooler periods.

Key words: preeclampsia, hypertension, pregnancy, temperature, humidity.

\section{INTRODUCTION}

Hypertensive disorders of pregnancy are responsible for a large proportion of cases of maternal mortality worldwide. ${ }^{1}$ Despite the numerous etiological causes for preeclampsia, including genetic, nutritional, immunological and infectious discussed so far, a consensus has yet to be reached. ${ }^{2}$ The most commonly accepted theory today, concerning the pathophysiological mechanism, is the immunological theory of poor placentation ${ }^{3}$ leading to endothelial lesion and diffuse vasospasm. Nevertheless, the factor responsible for triggering this mechanism continues to represent a challenge to investigators.

The effect of environmental conditions such as temperature, relative humidity of the air and the seasons of the year on the incidence of diseases has been recognized since the time of Hippocrates and is easily perceptible in

infectious diseases. In recent years, however, a seasonal pattern has also been recognized in the incidence of non-infectious diseases, ${ }^{4}$ such as cardiovascular and psychiatric disorders. Likewise, observations on the effect of environmental conditions on the incidence of preeclampsia have been documented. ${ }^{5,6}$ Although these remain controversial, recent systematic review on the subject found mostly consistent evidence of seasonal variation in the occurrence of the hypertensive disorders of pregnancy in both tropical and non-tropical regions. ${ }^{7}$

The aim of the present study was to evaluate the presence of an association between environmental temperature and the relative humidity of the air and the frequency of hypertensive disorders of pregnancy in a maternity teaching hospital in Recife, northeastern Brazil. 


\section{Methods}

Data collection began in September 2003 and the diagnostic records of all pregnant women admitted to the maternity of the Instituto de Medicina Integral Professor Fernando Figueira (IMIP) teaching hospital between April 2000 and December 2006 were included. Therefore, this descriptive and ecological study was of a prospective and retrospective nature. IMIP is a tertiary referral teaching hospital in the state of Pernambuco, Recife, Brazil and is responsible, together with other public hospitals in the region, for the care of most cases of high risk obstetric patients that depend on the public health system, the Brazilian Unified Health System (Sistema Unico de Sańde, SUS). In regards to the weather, Recife is located at the Northeast of Brazil, a city close to the Equator (latitude $8^{\circ} 04^{\prime} 03^{\prime \prime}$ South) and the climate is tropical. The local temperature and relative humidity of the air are characteristically high with small oscillation along the year and no greater variation has been observed along the period analyzed in this study.

The data referring to variations in temperature and the relative humidity of the air were obtained month by month for the study period from the meteorological office in Recife. Data collection at the meteorological stations was carried out by observers in accordance with international standards at three different times of the day. Time difference: 12 units of coordinated universal time $($ UTC $)=0900$ hours local time; 18 UTC $=1500$ hours; and 24 UTC $=2100$ hours local time. UTC, previously known as Greenwich Mean Time is the measurement of time used in meteorology worldwide in accordance with the regulations established by the World Meteorological Organization.

Mean monthly temperature was calculated from a mean of the maximum and minimum daily temperatures recorded in degrees Celsius $\left({ }^{\circ} \mathrm{C}\right)$ and the relative humidity of the air was quantified as a percentage $(\% \mathrm{RH})$ corresponding to the ratio between the absolute humidity of the air and the absolute humidity of the same air at saturation point at the same temperature.

The study was submitted to and approved by the ethics committee of this institution. Patients admitted in the period between December 2002 and May 2003 and in November and December 2003, as well as all the patients admitted throughout the entire year of 2004, were excluded from the study, since the diagnostic records for these periods were lost during a fire in the institute.

The obstetric data was collected from the diagnostic records available at the obstetrics department of this institute, in which all admissions of patients and their respective diagnoses are recorded.
At maternity admission all women have their blood pressure levels measured. In case in which hypertension (blood pressure equal to or greater than $140 \mathrm{mmHg}$ systolic or $90 \mathrm{mmHg}$ diastolic) is present, proteinuria is assessed and considered positive if $>300 \mathrm{mg}$ in $24 \mathrm{~h}$ urine or qualitative assessment of $2+$ in isolated sample or $1+$ in at least two samples. Eclampsia is diagnosed in the presence of seizures that could not be attributed to another cause in women with preeclampsia. Classification is made according to the diagnostic criteria of the National High Blood Pressure Education Program Working Group on High Blood Pressure in Pregnancy. ${ }^{8}$ For the present study, all diagnoses of prior systemic arterial hypertension or mild, severe or superimposed preeclampsia, pregnancy related hypertension or eclampsia were considered hypertensive disorders of pregnancy and these were the data considered for analysis.

For each month, the percentages of deliveries of women with hypertensive disorders of pregnancy were calculated. February was chosen as reference category because it had the lowest incidence of hypertensive disorders of pregnancy. The relative chance of hypertensive disorders of pregnancy for each other month was estimated by odds ratio.

For the statistical analysis, tables were constructed showing the frequency distributions of hospitalizations due to hypertensive disorders of pregnancy and the number of deliveries month by month. These data were then correlated with the monthly variation in relative humidity of the air and temperature. The Pearson coefficient was calculated to evaluate the correlation between the frequency of hypertensive disorders of pregnancy in each calendar month and the seasonal variations (quantified according to mean monthly temperature and relative humidity of the air).

\section{Results}

Initially, all 35.342 pregnant women admitted at IMIP between April 2000 and December 2006 were taken into consideration for inclusion in the study. However, for the purpose of evaluating the incidence of hypertensive disorders, 9.217 patients had to be excluded because the data on their diagnoses at admission were lost in a fire.

The remaining available data of 26.125 pregnant women were analyzed in the present study. A total of 5.051 patients were admitted with hypertensive disorders of pregnancy during the study period, including women with diagnoses of mild, severe and superimposed preeclampsia, pregnancy-related hypertension and eclampsia. One hundred and eight patients were admitted with a 
diagnosis of eclampsia. The total incidence rate of cases of hypertensive disorders of pregnancy was $19.33 \%$, with the annual incidence registered as year 2000 (19,5\%), 2001 (25,56\%), 2002 (25,52\%), 2003 (19,3\%), 2004 (data lost in fire), 2005 (13,5\%), 2006 (13,2\%). The mean monthly incidence of hypertensive disorders of pregnancy was also calculated. February presented the lowest (9.95\%) and August the highest (21.54\%) incidences (figure 1).

A graph with the monthly incidence of hypertensive disorders of pregnancy distribution as well as the mean monthly temperature was constructed. Two antagonist "U" pattern curves may be observed on the column arrangements, demonstrating an inverse relation between temperature and the incidence of hypertensive disorders of pregnancy (figure 1).

\section{Discussion}

When analyzing the findings of the present study, it is important to remember the climatic characteristics of Recife, a coastal city located in the Northeast of Brazil, which has a tropical weather. Throughout the studied years, the mean monthly temperature varied from $24^{\circ} \mathrm{C}$ to $27^{\circ} \mathrm{C}$ and there were no significant variations in the relative humidity of the air (69-87\% RH). As a consequence, there are no clear season characteristics. Therefore, incidence variation was analyzed monthly instead of by seasons.

The large number of cases of hypertensive disorders of pregnancy admitted to this institute, which constituted $19.33 \%$ of all admissions, may be justified in view of the fact that this is a tertiary teaching hospital that serves as a regional referral center. Furthermore, the institute has the only obstetric intensive care unit in northeastern Brazil.

The results of the numerous studies that have been carried out on the correlation between environmental temperature, relative humidity of the air and sunlight intensity, and the incidence of hypertensive disorders at time of delivery and even around conception ${ }^{10}$ are conflicting.

A survey carried out over a 36-month period in 11.958 newborn infants, in the state of Mississippi, USA, inves-

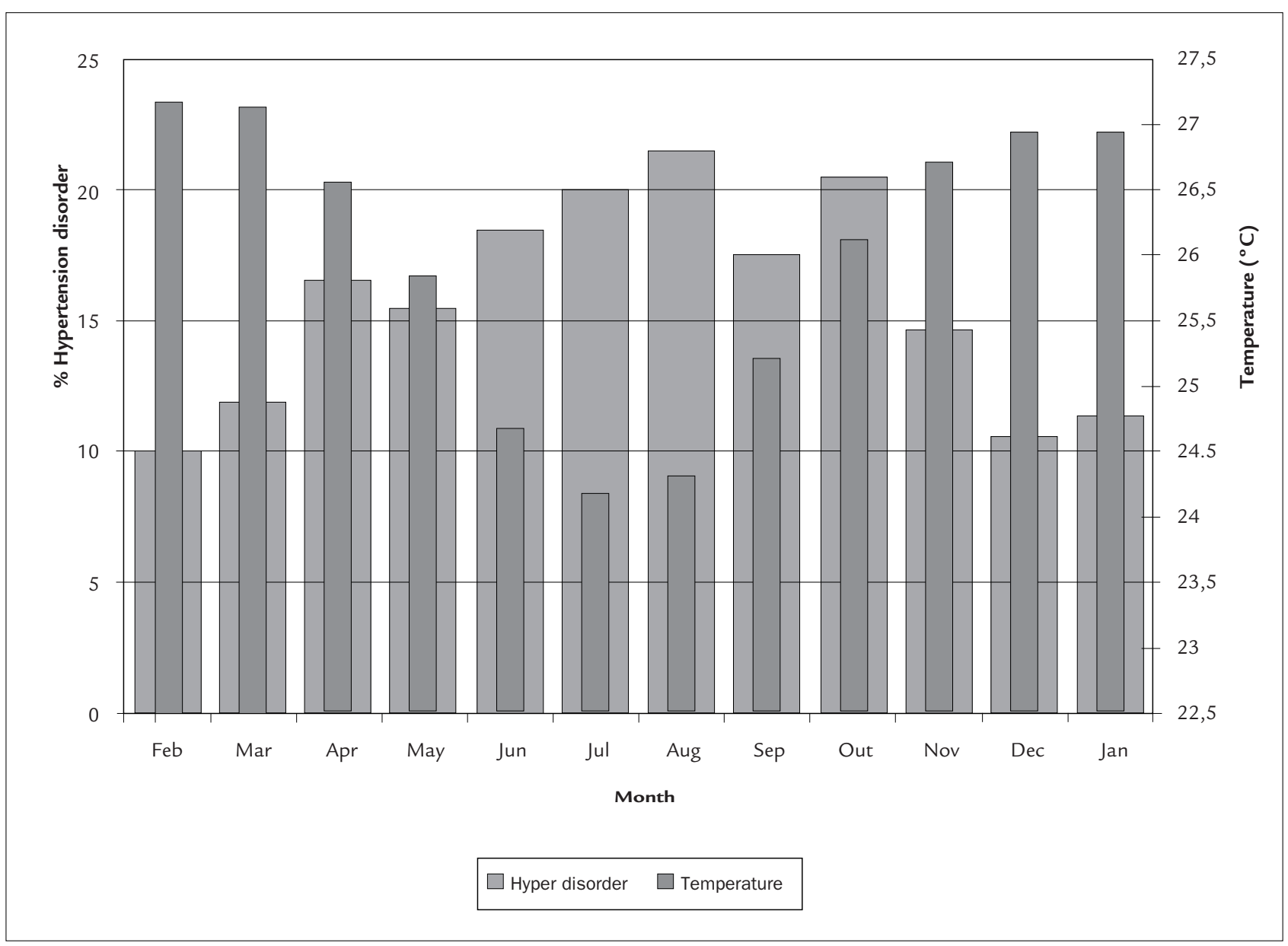

FIGURE 1 Monthly incidence of hypertensive disorders of pregnancy and mean monthly temperature 


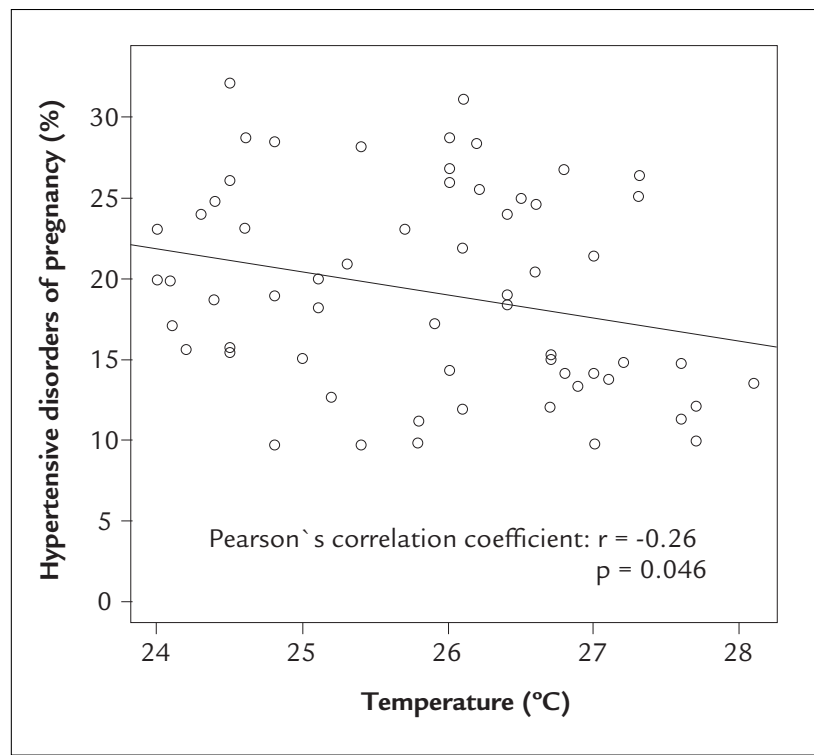

FIGURE 2 Pearson's correlation coefficient hypertensive disorders of pregnancy and mean monthly temperature

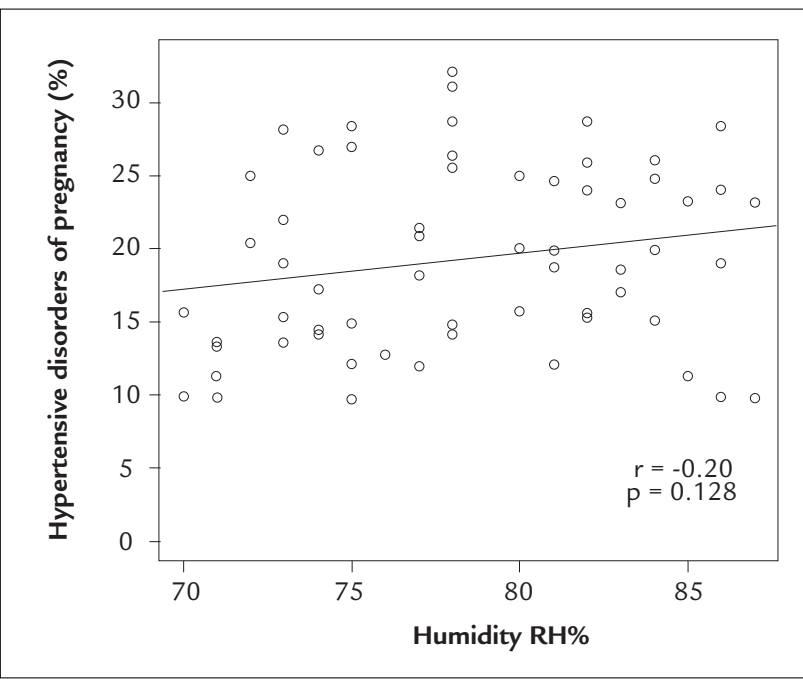

FIGURE 3 Pearson's correlation coefficient hypertensive disorders of pregnancy and mean relative air humidity \% RH

tigated 995 cases of hypertensive disorders of pregnancy (mild, severe and superimposed preeclampsia) and their distribution throughout the months of the year, according to mean temperature and relative humidity of the air, found no correlation between the incidence of hypertensive disorders and seasonality. ${ }^{11}$ However, another study, conducted in Kinshasa, Congo, with 17.592 women included, observed a higher incidence of preeclampsia in the driest months of the year $(6 \% v s .13 \%){ }^{12}$

On the other hand, a recent analysis on the monthly variation of preeclampsia among Bedouin and Jewish parturients in the Negev showed a similar U-shaped pattern in the incidence of preeclampsia. They have also found similar findings on the monthly incidence according to the weather, presenting the lowest incidence of preeclampsia during the hottest months and the highest incidence was observed during the local winter months ${ }^{12}$. Furthermore, an analysis of the data contained in the Norwegian Medical Birth Records, carried out for the period 1967-1998 and including 1.869 .388 births, reported an incidence of preeclampsia of $2.77 \%$, with a greater frequency in winter compared to summer. ${ }^{13}$ A study with almost 6.000 eclampsia parturients in Nigeria had similar findings. ${ }^{14}$ These findings are consistent with the results of the present study.

Another study carried out in Kuwait with respect to the period 1992-1994 and involving 28.262 births, 1.457 cases of pregnancy-induced hypertension and 692 cases of preeclampsia also reported a higher rate of preeclampsia in November, when the mean temperature was $20.9^{\circ} \mathrm{C}$ and humidity was $53.2 \%$ compared to the lower rate found in August when temperatures are higher and relative humidity of the air is lower (temperature $37.7^{\circ} \mathrm{C}$ and humidity $19.5 \%) \cdot{ }^{15}$ Similar findings, showing a higher rate of increased blood pressure in pregnant women in winter and spring, have also been reported in surveys carried out in Pittsburgh, United States of America (USA). ${ }^{16}$

In India, a study was carried out to determine the existence of a similar correlation between hypertensive disorders of pregnancy and the monsoon months of June, July and August, when humidity reaches $85 \%$, and the other months of the year when humidity is at $70 \%$. In 29.562 deliveries registered in that study, 1.238 patients (4.18\%) developed preeclampsia and, of these, $34(0.11 \%)$ went on to develop eclampsia. No correlation was found between the incidence of preeclampsia and the two periods studied, whereas a significant correlation was found between the episodes of eclampsia and the dry season compared to the rainy season $(0.2 \%$ versus $0.08 \% ; \mathrm{p}=0.01) .{ }^{17}$

Despite the divergence in the results reported in different parts of the world with respect to the possible effect of the environment on the incidence of hypertensive disorders of pregnancy, there would appear to be a trend towards a higher incidence of the disease in the cooler months. The biological explanation in support of this theory would be that lower temperatures would affect the incidence of eclampsia by accentuating the vasospasm that is characteristic of the disease. ${ }^{15}$

The findings of the present study support this theory, with a higher incidence of hypertensive disorders of pregnancy in the cooler months throughout the entire six-year study period. It is important to emphasize that this correlation was found even in this part of the world, 
a low latitude tropical region in which there is little variation in temperature or humidity throughout the year. No correlation was found with respect to relative humidity of the air; however, some points should be taken into consideration.

The demonstration of an expected pattern of monthly incidence of hypertensive disorders of pregnancy throughout the year may contribute to the planning of health systems. The awareness of health authorities of these variations facilitates the elaboration of adequate strategies in every different level of actions, such as personnel, logistics, equipments and supplies.

Since this is an ecological study, the survey is restricted to diagnosis at admission prior to delivery, and to the evolution of the patients whose diagnosis may have changed such as, for example, the case of a patient admitted with preeclampsia who went on to develop eclampsia, was not recorded. It is also important to emphasize that since the data were collected from admission records, it was both difficult to differentiate between the various diagnoses of hypertensive disorders of pregnancy, (i.e.) all the pregnant women with a prior history of hypertension were included, and to identify if these women were being admitted for treatment or delivery. Since the probable reason for the effect of the environment on the incidence of preeclampsia would be a potential stimulus exerted by the cold on the mechanism of generalized vasoconstriction of the disease - a pathophysiological mechanism different from that involved in systemic arterial hypertension - it is reasonable to conclude that this correlation merits further investigation in future studies.

\section{Conclusion}

The incidence of diagnosis of hypertensive disorders of pregnancy may be affected by variations in temperature, especially during cooler periods. Further studies, conducted prospectively, and including variables such as gestational age and clearly defined diagnosis criteria of these disorders should be conducted to additionally contribute to future elucidation of the influence of weather on the incidence of hypertensive disorders of pregnancy.

\section{AcKNOWLEDGEMENTS}

The authors gratefully acknowledge the collaboration of the $3^{\text {rd }}$ District Meteorology Office of the city of Recife in providing the data used in this study.

\section{RESUMO}

Hipertensão, gestação e clima: a sazonalidade contribui?
Objetivo: O objetivo do presente estudo foi avaliar a associação entre a temperatura e umidade relativa do ar e a incidência de síndromes hipertensivas gestacionais.

Métodos: Um estudo ecológico, prospectivo e retrospectivo, foi conduzido em uma maternidade-escola, na cidade do Recife, Brasil. Dados de todas as 26.125 gestantes, admitidas entre os anos de 2000 e 2006, foram analisados e 5.051 mulheres tiveram o diagnóstico de síndrome hipertensiva gestacional no momento da admissão. A incidência percentual foi calculada mensalmente, por número de partos. Dados referentes à temperatura média mensal e umidade relativa do ar mensal foram coletados e comparações feitas mês a mês quanto à incidência da doença. O mês de fevereiro foi escolhido como mês de referência por conta da sua menor incidência. O risco relativo de síndrome hipertensiva gestacional para cada outro mês foi calculado por odds ratio e o coeficiente de correlação de Pearson foi utilizado para calcular a relação entre a incidência da doença e a média mensal de temperatura e umidade relativa do ar.

Resultados: O mês de fevereiro apresentou a menor incidência mensal da doença $(9,95 \%)$ e agosto, a maior (21,54\%). O coeficiente de correlação de Pearson demonstrou maior incidência de síndromes hipertensivas gestacionais nos meses mais frios $(r=-0,26 ; p=0,046)$, e nenhum efeito significativo da umidade relativa do ar $(\mathrm{r}=0,20$; $\mathrm{p}=0,128)$.

Conclusão: A incidência de síndromes hipertensivas gestacionais parece ser afetada por variações na temperatura, com menor incidência nos períodos mais frios.

Unitermos: pré-eclâmpsia, hipertensão, gravidez, clima.

\section{References}

1. Khan KS, Wojdyla D, Say L, Gülmezoglu AM, Van Look PF. WHO analysis of causes of maternal death: a systematic review. Lancet. 2006;367(9516):1066 74

2. Mignini LE, Villar J, Khan KS. Mapping the theories of preeclampsia: the need for systematic reviews of mechanisms of the disease. Am J Obstet Gynecol. 2006;194(2): 317-21.

3. Roberts JM, Cooper DW. Pathogenesis and genetics of preeclampsia. Lancet 2001;357(9249):53-6

4. Siffel C, Alverson CJ, Correa A. Analysis of seasonal variation of birth defects in Atlanta. Birth Defects Res A Clin Mol Teratol. 2005;73(10):655-62.

5. Tam WH, Sahota DS, Lau TK, Li CY, Fung TY. Seasonal variation in preeclamptic rate and its association with the ambient temperature and humidity in early pregnancy. Gynecol Obstet Invest. 2008;66(1):22-6.

6. Gerber Y, Jacobsen SJ, Killian JM, Weston SA, Roger VL. Seasonality and daily weather conditions in relation to myocardial infarction and sudden cardiac death in Olmsted County, Minnesota, 1979 to 2002. J Am Coll Cardiol. 2006;48(2):287-92.

7. TePoel MR, Saftlas AF, Wallis AB. Association of seasonality with hypertension in pregnancy: a systematic review. J Reprod Immunol. 2011;89(2):140-52.

8. Report of the National High Blood Pressure Education Program Working Group on High Blood Pressure in Pregnancy. Am J Obstet Gynecol. 2000;183(1):S1-S22. 
9. Algert CS, Roberts CL, Shand AW, Morris JM, Ford JB. Seasonal variation in pregnancy hypertension is correlated with sunlight intensity. Am J Obstet Gynecol. 2010;203(3):215.e1-5.

10. Magann EF, Perry KG Jr, Morrison JC, Martin JN Jr. Climatic factors and preeclampsia-related hypertensive disorders of pregnancy. Am J Obstet Gynecol. 1995;172(1 Pt 1):204-5.

11. Elongi JP, Tandu B, Spitz B, Verdonck F. Influence of the seasonal variation on the prevalence of preeclampsia in Kinshasa. Gynecol Obstet Fertil. 2011;39(3):132-5

12. Shental O, Friger M, Sheiner E. Ethnic differences in the monthly variation of preeclampsia among Bedouin and Jewish parturients in the Negev. Hypertens Pregnancy. 2010;29(3):342-9.
13. Magnu P, Eskild A. Seasonal variation in the occurrence of preeclampsia. BJOG. 2001;108 (11):1116-9.

14. Okafor U, Efetie E, Ekumankama O. Eclampsia and seasonal variation in the tropics - a study in Nigeria. Pan Afr Med J. 2009;2:7.

15. Makhseed M, Musini VM, Ahmed MA, Monem RA. Influence of seasonal variation on pregnancy-induced hypertension and/or preeclampsia. Aust N Z J Obstet Gynaecol. 1999;39(2):196-9.

16. Bodnar LM, Daftary A, Markovic N, Schatzman CL, Roberts JM. Seasonal variation in gestational blood pressure. Hypertens Pregnancy. 2006;25(3):271 83.

17. Subramaniam $V$. Seasonal variation in the incidence of preeclampsia and eclampsia in tropical climatic conditions. BMC Womens Health. 2007;7:18 